\title{
DBVE-PC Regimen
}

National Cancer Institute

\section{Source}

National Cancer Institute. DBVE-PC Regimen. NCI Thesaurus. Code C67175.

A regimen consisting of doxorubicin, bleomycin, vincristine, etoposide, prednisone and cyclophosphamide, given in combination with radiation therapy and used for the treatment of high-risk, childhood Hodgkin lymphoma. 